\title{
Diferenciação de diagnósticos e tratamentos entre alergia e intolerância ao leite
}

\author{
Differentiation of diagnoses and treatments between millk allergy and intolerance \\ Diferenciación de diagnósticos y tratamientos entre alergia e intolerancia a la leche
}

\section{Resumo}

A Alergia a Proteína do Leite de Vaca (APLV) é uma alergia alimentar, mais frequente em crianças e é desencadeada por uma resposta imunológica. A Intolerância à Lactose (IL) está relacionada com a má absorção da lactose devido a inatividade ou deficiência da enzima lactose. A fim de resguardar a saúde da população, principalmente as crianças, é objetivado demonstrar a importância do diagnóstico da IL e da APLV, a diferenciação entre as condições e seus diagnósticos e tratamento. O diagnóstico da APLV é realizado através de anamnese, teste físico, pesquisa de anticorpos e o teste de provocação oral. O tratamento primário é a exclusão do consumo do leite de vaca, podendo incluir o uso de corticoides e anti-histamínicos. O diagnóstico da IL pode ser realizado por teste de tolerância e medição da atividade da lactase. O tratamento da IL é a suspensão do consumo do leite e/ou a terapia de reposição da enzima lactase. O método Food Detective não é adequado para diagnosticas APLV ou IL. O diagnóstico das duas condições deve ser realizado com cautela, visto que a exclusão do leite da alimentação pode interferir nos níveis de nutrientes necessários, principalmente nas crianças.

Palavras-chave: Leite de vaca; Alergia; Intolerância; Diagnostico.

\begin{abstract}
Allergy to Cow's Milk Protein (ACMP) is a food allergy, more common in children, and it is triggered by an immune response. Lactose Intolerance (LI) is related to lactose malabsorption due to inactivity or deficiency of lactose enzyme. The objective of this study is to demonstrate these two conditions and their diagnosis and treatment. The diagnosis of ACMP is made through anamnesis, physical test, antibody research and the Oral Provocation Test. The primary treatment is the exclusion of cow's milk consumption, which can include the use of corticosteroids and antihistamines. The diagnosis of LI can be performed by tolerance test and measurement of lactase activity. The treatment of LI is the suspension of milk consumption and/or the therapy of replacement of the enzyme lactase. The Food Detective method is not suitable for ACMP or LI diagnostics. Both conditions diagnosis should be made with caution, since the exclusion of milk from diet may interfere with the nutrient levels needed, especially in children.
\end{abstract}

Keywords: Cow milk; Allergy; Intolerance; Diagnosis.

\section{Resumen}

La alergia a la proteína de la leche de vaca (APLV) es una alergia alimentaria, más frecuente en los niños y se desencadena por una respuesta inmune. La intolerancia a la lactosa (IL) está relacionada con la malabsorción de lactosa debido a la inactividad o deficiencia de la enzima lactosa. Con el fin de salvaguardar la salud de la población, especialmente de los niños, se pretende demostrar la importancia del diagnóstico de IL y APLV, la diferenciación entre condiciones y sus diagnósticos y tratamiento. El diagnóstico de APLV se realiza a través de anamnesis, prueba física, investigación de anticuerpos y prueba de provocación oral. El tratamiento primario es la exclusión del consumo de leche de vaca, y puede incluir el uso de corticosteroides y antihistamínicos. El diagnóstico de IL se puede realizar mediante prueba de tolerancia y medición de la actividad de la lactasa. El tratamiento de la IL es la suspensión del consumo de leche y/o la terapia de reemplazo enzimático de lactasa. El método Food Detective no es adecuado para el diagnóstico de APLV o IL. El diagnóstico de ambas condiciones debe llevarse a cabo con precaución, ya que la exclusión de la leche de la alimentación puede interferir con los niveles de nutrientes necesarios, especialmente en los niños.

Palabras clave: Leche de vaca; Alergia; Intolerancia; Diagnóstico. 


\section{Introdução}

A alimentação é crucial para o desenvolvimento de crianças, o que inclui a necessidade de ingestão de alimentos nutritivos como o leite advindo de fontes animais, principalmente bovinos. O leite é uma fonte de nutrientes importante para o desenvolvimento ósseo, principalmente pelo seu alto teor de cálcio (Moratoya et al., 2013; Muniz et al., 2013).

Entretanto, adultos e principalmente crianças podem apresentar complicações com a ingestão deste alimento, que podem ser temporárias ou permanentes, como por exemplo intolerâncias ou alergias. Problemas associados à ingestão de leite animal por crianças em tenra idade, em função da diferença de composição em relação ao leite humano, podem causar problemas como vômitos ou mesmo diarreia (Lopes et al., 2020), sintomas estes que podem ser atribuídos erroneamente à intolerância alimentar ou alergia alimentar, ocasionando uma restrição alimentar. Uma suposição ou diagnostico incorreto sobre essas condições podem dificultar a vivência e prejudicar o bom desenvolvimento do corpo, principalmente de crianças.

A Alergia a Proteína do Leite de Vaca (APLV) consiste numa alergia alimentar que não é incomum ocorrer em crianças, principalmente nas que possuem até três anos de idade, devido à imaturidade do sistema imunológico (Ferreira et al., 2014a). A APLV está ligada a fatores imunológicos, pois desenvolve uma defesa a uma proteína desconhecida para o organismo, no caso as proteínas do leite, liberando anticorpos, citocinas e histaminas (Gasparin et al., 2010). A APLV pode causar diversos sintomas no indivíduo acometido, tais como náuseas, vômitos, diarreia, dores abdominais, refluxo gástrico, choque anafilático e outros de importância clínica (Ferreira et al., 2014a; Ramos et al., 2013).

Diferente da APVL, a Intolerância à Lactose (IL) não está ligada a reações imunológicas, mas sim da incapacidade do corpo em digerir um açúcar conhecido como lactose. Este açúcar, que está presente no leite, é importante na absorção do cálcio, aporte energético e no desenvolvimento e crescimento da flora intestinal (Toméi, 2016). A má absorção da lactose está relacionada com a diminuição, inatividade ou ineficiência de atividade da enzima lactase, responsável por hidrolisar a lactose. Indivíduos acometidos com a IL podem desencadear sintomas como diarreias, dores abdominais e flatulências e podem melhorar quando há a interrupção do consumo do leite e seus derivados. De forma resumida, a IL é caracterizada pelo aparecimento de sintomas abdominais advindos da má absorção da lactose (Mattar \& Mazo, 2010).

Devido a ocorrência de alguns sintomas semelhantes, a APLV e a IL são rotineiramente confundidas pela população. De forma geral, o diagnóstico precoce da IL ou APLV é importante para a melhoria da qualidade de vida dos indivíduos acometidos, uma vez que a privação do consumo desses alimentos pode interferir na saúde e nos hábitos alimentares. Logo, é importante o conhecimento sobre a diferenciação das duas condições para que haja um tratamento e diagnóstico mais assertivo, uma vez que são normalmente confundidas. A identificação correta de um quadro de alergia, ou mesmo intolerância ao leite, pode ajudar os profissionais ou cuidadores a instruírem melhor os pacientes sobre as restrições, tratamentos e outros aspectos que podem ser relevantes na qualidade de vida do paciente (Andrade et al., 2020).

O objetivo deste trabalho é caracterizar e diferenciar as condições de APLV e IL, assim como destacar a importância e as formas de diagnóstico de ambas, assim como seus tratamentos e restrições; apontando os problemas relacionados ao tema.

\section{Metodologia}

Foi realizada uma pesquisa bibliográfica sistemática (Pereira et al., 2018), baseada artigos retirados de bancos de dados eletrônicos da Biblioteca Virtual em Saúde, Scientific Electronic Library Online - Scielo, Lilacs, PubMed e Google Acadêmico. Também foram consultados os seguintes órgãos nacionais e internacionais sobre o assunto: CFN (Conselho Federal de Nutrição), ASBAI (Associação Brasileira de Alergia e Imunologia), ANS (Agência Nacional de Saúde), ASCIA (Australian Society of Clinical immunology and Allergy), AACI (Allergy, Asthma \& clinical immunology) e EAACI (European Academy of Allergy and Clinical Immunology). Para critérios de inclusão dos artigos pesquisados, foram considerados trabalhos cujo acesso ao periódico é livre, artigos em língua portuguesa, publicados dentro de um período de até 15 anos e que 
estão relacionados à temática. Foram utilizados descritores como: Alergia a Proteína do Leite de Vaca, Intolerância à lactose, diagnóstico e tratamento.

\section{Resultados e Discussão}

\subsection{Alergia a proteína do leite de vaca (APLV)}

As alergias alimentares interferem significativamente na qualidade de vida dos indivíduos acometidos. Estima-se que o crescimento de casos de alergias alimentares deve-se ao fato das mudanças de hábitos alimentares, como alimentação fora de casa e o consumo de produtos industrializados (Souza et al., 2013; Ramos et al., 2013).

A APLV constitui uma alergia frequente, sobretudo em crianças, em função do seu sistema imunológico não estar desenvolvido por completo. Apesar de crianças serem suscetíveis a alergias nos primeiros anos de idade, a maioria delas, após os dois anos de idade, cessam os sintomas de alergias, incluindo a APLV (Costa et al., 2012).

A APLV é resultante de uma resposta imunológica após exposição ao leite. O leite de vaca possui cerca de 20 proteínas que podem causar sensibilidade, como a $\alpha$-lactoalbumina e $\alpha$-lactoglobulina e caseína (Asbai \& Sban, 2012). As alergias, em geral, podem ser classificadas em três tipos: mediadas por IgE, não mediadas por IgE e a mista (combinação das duas).

As alergias mediadas por IgE causam reações rápidas, normalmente logo após o contato do organismo com as proteínas alergênicas do leite. São caracterizadas pela formação de anticorpos. Já as reações não mediadas por IgE são mediadas por outras células (Linfócitos $\mathrm{T}$ e citocinas pró inflamatórias); as reações não mediadas por IgE podem apresentar um intervalo variável para ocorrer (Santos et al., 2019).

É importante ressaltar que a ocorrência de Refluxo Gastrointestinal (RG) em crianças é frequente, em função de diversos fatores. Geralmente a ocorrência de RG é diretamente relacionada com a APLV, sendo verdade em alguns casos. Entretanto, nem sempre RG e APLV estão correlacionados, gerando uma situação de privação de alimentos e uso desnecessário de medicamentos, podendo causar prejuízos ao desenvolvimento da criança (Ferreira et al., 2014a). Portanto, é de suma importância realizar um diagnóstico adequado da APLV, ao invés de atribuir sua ocorrência apenas à visualização de sintomas. Na Tabela 1 estão relacionados os principais sinais e sintomas relacionados com a APLV, conforme o mecanismo de defesa desencadeado (mediado por IgE ou não mediado por IgE). 
Tabela 1 - Principais sintomas relacionados a APLV.

\begin{tabular}{|c|c|c|c|}
\hline \multirow{7}{*}{ Mediadas por $\mathrm{IgE}$} & \multicolumn{3}{|c|}{ Reações } \\
\hline & Gastrointestinais & Pele & Sistema Respiratório \\
\hline & Diarreia & Prurido & Prurido nasal \\
\hline & Náuseas & Urticária & Rinorreia \\
\hline & Vômitos & Angioedema & Congestão nasal \\
\hline & Dores abdominais & & Tosse crônica \\
\hline & & & Dificuldades respiratórias \\
\hline & Cólicas infantis & Prurido & \\
\hline & Refluxo gastrointestinal & Eritema & \\
\hline Não mediadas por IgE & Aversão alimentar & Dermatite atópica & \\
\hline & Anemia & & \\
\hline & Sangue/muco nas fezes & & \\
\hline
\end{tabular}

Fonte: Adaptado de Ferreira et al. (2014a).

\subsection{Diagnóstico e tratamento da alergia a proteína do leite de vaca}

O diagnóstico da APLV consiste basicamente em cinco tipos: anamnese e exame físico, restrição de dieta, teste de pesquisa de anticorpos IgE específicos, Teste Cutâneo Alérgico (TCA) e Teste de Provocação Oral (TPO). O TPO é o teste final para conclusão do diagnóstico (Asbai \& Sban, 2012; Rocha, 2018).

A anamnese e o exame físico constituem uma parte fundamental para o início do diagnóstico. A história clínica do paciente pode ajudar a determinar um diagnóstico mais preciso, daí a importância da anamnese. Entretanto, para atestar o quadro de APLV o exame físico é requerido, uma vez que é possível haver distorções nos relatos dos sintomas por parte do paciente ou cuidador (Asbai \& Sban, 2012). O exame físico deve buscar sinais ou comorbidades relativas à APLV (Rocha, 2018; Santin et al., 2018).

Quando é observado algum sintoma característico relativo à APLV, é recomendada a restrição de dieta, que consiste na eliminação completa do consumo de leite e seus derivados. A restrição, em um primeiro momento, é importante a fim de evitar males ao paciente (Brisotti et al., 2018). Entretanto a restrição alimentar não deve ser mantida sem um diagnóstico acerca do possível quadro alérgico, onde se faz necessário o acompanhamento médico e clínico do caso (Asbai \& Sban, 2012).

$\mathrm{O}$ teste para detecção de $\mathrm{IgE}$ específica para proteína do leite (exemplos: caseína, alfa-lactoalbumina, betalactoglobulina e sero-albumina bovina) pode ser realizado in vivo e in vitro. O teste in vivo consiste em um teste cutâneo de hipersensibilidade utilizando proteína do leite, normalmente caseína. Já o teste in vitro consiste na identificação de anticorpos IgE no sangue; é utilizado quando o in vivo é impossibilitado (lesões na pele, dermografismo e uso de medicamentos contínuos, como os histamínicos). É importante ressaltar que o teste para detecção de IgE específica para proteína do leite não deve ser utilizado como único método para o diagnóstico, sendo recomendado o exame de TPO para a sua conclusão. Entretanto, o TPO é recomendado quando existe a confirmação da suspeita de APLV após a aparição de reações agudas (Asbai \& Sban, 2012; Garcia et al., 2016).

O TCA é um teste rápido, de resposta rápida, fácil, seguro, minimamente invasivo e reprodutível. O TCA é útil como diagnostico, principalmente quando associado com o IgE, onde relaciona-se a concentração de IgE sérica com a medida do diâmetro das pápulas. Apesar de ser possível aplicar o TCA em qualquer idade, em crianças de até 2 anos e idosos acima de 65, as pápulas geradas pelo teste são menores, de forma que este teste não é recomendado para este público. Com o 
acompanhamento de um quadro de APLV por meio da TCA, é possível observar a redução do tamanho das pápulas e consequentemente o período certo para se realizar um TPO (Neves et al., 2016; Franco et al., 2018).

O TPO é o método de maior confiabilidade para a confirmação ou exclusão do diagnóstico de alergias alimentares, como a APLV. O teste é realizado administrando quantidade gradual de leite de vaca, iniciando com uma dose inferior ao que normalmente produziria sintomas, aumentando até uma dose adequada para a idade. Esse teste deve ser realizado preferencialmente em ambiente hospitalar, visto que pode apresentar reações imediatas, sendo preciso um atendimento emergencial (Santin et al., 2018; Ferreira et al., 2014b).

O TPO é dividido em três formas: aberto, quando é oferecido o leite de vaca em forma natural e todos os envolvidos estão cientes do que está sendo administrado; simples cego, onde é utilizado leite de vaca e um placebo, sendo que somente o profissional sabe o que está sendo administrado; e Duplo Cedo Placebo Controlado (DCPC), onde é administrado leite de vaca e placebo, porém o médico, pais e paciente não sabem o teor, sendo necessário uso de codificação e uma pessoa não envolvida no tratamento para a condução do teste. O TPO aberto é preferencialmente utilizado em crianças menores de 3 anos; já o DCPC, por ser mais caro, é utilizado em protocolos científicos ou quando é necessário eliminar sintomas subjetivos (Santin et al., 2018; Ferreira et al., 2014b).

O tratamento da APLV é a exclusão do leite de vaca e seus derivados da dieta do paciente. É necessário cautela para a exclusão do consumo, uma vez que o alimento é importante como fonte nutricional, sobretudo em crianças. O tratamento medicamentoso na APLV é utilizado nos casos de crise aguda ou manifestações crônicas, através de corticoides e antihistamínicos (Brisotti et al., 2018). A adrenalina intramuscular pode ser utilizada em casos de reações anafiláticas (Ferreira et al., 2014b).

\subsection{Intolerância a lactose}

Um dos carboidratos presentes no leite é a lactose, que deve ser hidrolisada por meio da enzima lactase, gerando a glicose e galactose. Após o desmame, a lactase tende a diminuir sua atividade e quantidade, resultando em uma absorção ineficiente da lactose (Mattar \& Mazo, 2010). Estima-se que no Brasil existem certa de 35 a 40 milhões de pessoas adultas que apresentam algum desconforto após a ingestão de leite; destes, 80\% são negros (Branco et al., 2018).

A falta da hidrólise da lactose faz com que ela não seja absorvida no intestino delgado, passando diretamente para o cólon. No cólon, a lactose é fermentada pela flora intestinal, que a converte em ácidos graxos de cadeia curta e gases, tais como o gás hidrogênio $\left(\mathrm{H}_{2}\right)$ e o gás carbônico $\left(\mathrm{CO}_{2}\right)$. Os gases formados podem causar dores abdominais, assim como sensação de inchaço no abdome, levando o indivíduo a um quadro de flatulência. Ainda, a fermentação da lactose no intestino pode ocasionar a acidificação do conteúdo colônico e aumento da carga osmótica, levando a uma maior secreção de eletrólitos e fluidos, o que, por sua vez, pode ocasionar fezes pastosas e diarreia (Grenov et al., 2016).

A IL pode ser classificada como primária, secundária e congênita. A primária, também chamada hipolactasia primária adulta, é a forma mais comum e prevalente na população. É caracterizada pela redução fisiológica (total ou parcial) da produção da lactase nas células intestinais. A IL secundária caracteriza-se pela existência de situação fisiológica - perda de células epiteliais, que produzem a lactase -, levando à intolerância devido à má absorção ou digestão da lactose. Alguns fatores podem ocasionar as lesões na mucosa do intestino que interferem na produção da lactase como, por exemplo, a quimioterapia, diarreias, gastroenterites, radioterapia, infecções virais, parasitoses e infecções pelo HIV (Gasparin et al., 2010; Mattar \& Mazo, 2010).

Uma característica importante da IL secundária é ser reversível quando o paciente inicia o tratamento da doença base, recuperando a lesão da mucosa. Já a IL congênita é uma herança genética que acomete recém-nascidos nos seus primeiros dias de vida. Essa IL, se não diagnosticada rapidamente, pode levar a óbito. É uma condição rara, mas extremamente grave. 
Consiste em uma doença autossômica recessiva e caracteriza-se pela mutação no gene da lactase, ocorrendo ausência total ou parcial da enzima. Essa condição leva a um quadro clínico que pode desenvolver desidratação, acidose metabólica, diarreia ácida, acidose renal e vômito predominante (Gasparin et al., 2010; Mattar \& Mazo, 2010).

\subsection{Diagnóstico e tratamento da intolerância a lactose}

O diagnóstico da IL deve ser realizado com cautela, visto que com sua confirmação, o tratamento principal é a exclusão, restrições ou diminuição do consumo de leite. O diagnóstico da IL normalmente é realizado pela ingestão de lactose em jejum e após algumas horas é retirada amostra de sangue para medir a quantidade de glicose presente no organismo (Cunha et al., 2008).

O teste de tolerância consiste na ingestão de uma dose de lactose (25-50 g) em jejum. Após períodos pré-determinados colhe-se amostras de sangue para analisar a quantidade de glicose no sangue, utilizando a técnica de curva glicêmica. Caso haja a absorção da lactose, os níveis glicêmicos tendem a aumentar (Cunha et al., 2008).

O teste de medição da atividade de lactase mede a atividade da enzima no intestino delgado, por meio de biópsia da mucosa duodenal. Este método é padrão para o diagnóstico de IL a primária e secundária. Uma das desvantagens do método é ser invasivo. Outra maneira de se diagnosticar a IL é pela análise das fezes (cor ou acidez), pois quando não absorvidos os açúcares não ingeridos podem alterar o pH e a coloração das fezes (Barreto, 2010).

O teste respiratório de hidrogênio é considerado o padrão-ouro para o diagnóstico de IL. O teste é baseado na produção de hidrogênio advindo da fermentação da lactose que não foi absorvida pelo organismo. $O$ hidrogênio resultante dessa fermentação entra na corrente sanguínea e é expirado pelo pulmão. É um exame que apresenta alta sensibilidade e especificidade, ajudando-o a ser o padrão para o diagnóstico da condição (Silva et al., 2019)

O tratamento inicial deve ser a suspensão temporária do consumo de leite e seus derivados, porém a exclusão total do consumo de lactose deve ser evitada, pois os alimentos que a contém são fontes importantes de nutrientes e vitaminas, o que pode acarretar deficiência nutricional, sobretudo de cálcio. Se não houver uma melhora com a medida anterior, é necessário intervenção medicamentosa, como terapia de reposição da enzima lactase exógena e/ou utilização de probióticos (Mattar \& Mazo, 2010).

A lactase pode ser encontrada através de algumas fontes, como rosas selvagens, plantas, amêndoas, organismos animais (tecido da pele, intestino, cérebro etc.); podendo ser obtida a partir de leveduras, bactérias e fungos (Cunha et al., 2008).

\subsection{Teste de Intolerância a alimentos mediada por IgG}

Atualmente é direcionado ao público exames que relacionam a ingestão de alimentos às concentrações de $\operatorname{IgG}$ a fim de verificar alergias ou intolerâncias alimentares. Esse tipo de exame é comumente conhecido pelo nome "Food Detective". Neste exame, amostras do sangue do paciente são expostas a diversos alimentos separadamente. Como resposta é observada, de forma qualitativa, a produção de IgG após o contato com o alimento (Biosys, 2008).

O que se pode avaliar destes resultados é que quando o valor de IgG para determinado alimento se mostra alto, isso indica que, em algum momento aquele alimento foi considerado um organismo estranho para o corpo, entretanto a resposta alta de IgG assegura que o organismo responde de forma adequada a aquele estímulo, de forma que se encontra imunizado. Por implicação lógica, esse efeito remete aos primeiros meses de vida, em que é necessário no mínimo 6 meses de aleitamento materno exclusivo, tendo em vista que o sistema imunológico da criança ainda está em desenvolvimento. Qualquer alimento dado à criança antes do término deste período, acabam por gerar uma resposta do sistema imunológico, gerando anticorpos 
IgG. Logo, a identificação da resposta de IgG significa que os anticorpos de memória criados em época remota do paciente foram ativados, pois houve a estes uma resposta alérgica no passado.

O teste de IgG, é erroneamente associado a alergias e principalmente a intolerância alimentar, entretanto raramente ele é bem interpretado. Primeiro, sendo o IgG um componente do sistema imunológico, ele não possui nenhuma relação com intolerâncias alimentares, as quais causam em geral desconfortos intestinais, não reações de dermatite atópica e refluxo gastroesofágico. Os indicativos da formação de IgG não indicam intolerância, muito pelo contrário, indicam resistência.

Na literatura científica já foram publicados pareceres e pesquisas indicando que esta técnica não é reprodutível, corroborando sua ineficácia para diagnosticar alergias ou mesmo intolerâncias. Dentre os órgãos nacionais e internacionais especializados no assunto que desacreditam o método associado ao IgG, podem ser citados o CFN (Conselho Federal de Nutrição), ASBAI (Associação Brasileira de Alergia e Imunologia), ANS (Agência Nacional de Saúde), ASCIA (Australian Society of Clinical immunology and Allergy), AACI (Allergy, Asthma \& clinical immunology) e EAACI (European Academy of Allergy and Clinical Immunology). Ou seja, tanto órgãos nacionais como entidades internacionais expõem que o Food Detective não é um parâmetro para qualquer detecção de intolerâncias ou alergias alimentares. Além de não recomendar o teste, pois não há consistência e nem comprovação de que esta técnica funcione, sugerem que ela estaria indicando os alimentos aos quais o paciente possui tolerância alimentar, e não intolerância (Asbai, 2016; Cnf, 2012; Ascia, 2014; Carr et al., 2012; Bock, 2010).

\subsection{Diferenciação entre alergias e intolerâncias}

Alergias em geral são respostas do sistema imunológico provocadas pela presença de um corpo identificado como estranho pelo organismo. Ou seja, caso algo seja ingerido, o que pode ser uma substância ou mesmo um microrganismo invadindo o corpo, nosso sistema de defesa, denominado sistema imunológico, vai ser ativado para neutralizar esta substância e eliminá-la do organismo, evitando a sua proliferação e efeitos danosos que ela poderia causar no mesmo. Quando o sistema imunológico é ativado em função da presença de uma substância estranha ao corpo (especificamente no caso de alergias), são liberadas para combater este intruso diversas proteínas do sistema imunológico, sendo estas conhecidas como anticorpos, denominados Imunoglobulinas (Ig). No caso específico de alergias, são liberadas as Imunoglobulinas do tipo E, denominadas IgE. Ou seja, as IgE são liberadas no caso de uma substância alérgica penetrar o organismo (Calich \& Vaz, 2009).

As Igs, fazem parte do sistema imunológico, agindo diretamente sobre corpos estranhos a fim de neutralizá-los. Visualmente, quando ocorre esta neutralização, são observados os sintomas característicos da resposta do organismo à substância invasora, como por exemplo, respostas inflamatórias de inchação, vermelhidão entre outras que são os sintomas de alergia. Pode-se inferir, no caso de alergias, que o IgE atua de forma imediata quando uma substância atua como um corpo estranho, então neste caso caracteriza-se como um quadro de "alergia" a esta substância (Asbai \& Sban, 2012).

Outro componente do sistema imunológico são as proteínas Ig do tipo G, denominadas IgG. Estes componentes são conhecidos como anticorpos de memória, ou seja, a presença deste em alta quantidade sugere uma alta imunidade ou resistência natural da pessoa a certo corpo invasor. Para exemplificar podemos citar a doença catapora. É sabido que esta doença é contraída apenas uma vez na vida (com raras exceções), de forma que, após o primeiro contato a pessoa fica imune à doença. Analisando uma pessoa que esteja infectada com a catapora, observa-se que seu sistema imunológico se encontra ativo, ou seja, os anticorpos estão atuando combatendo os agentes causadores da doença, no caso os anticorpos IgM, que são responsáveis por combater microrganismos invasores. Após a cura da doença, os níveis de IgM do sujeito vão diminuir, pois ele não está mais sendo exposto ao agente da catapora, entretanto naturalmente vai ocorrer o aumento das taxas de IgG, pois estes são os anticorpos de memória (Calich \& Vaz, 2009). 
No caso de o agente da catapora agir novamente nessa pessoa, estes vão esbarrar nos anticorpos IgG presentes na corrente sanguínea do indivíduo, os quais vão elevar-se em concentração a fim de combater o corpo invasor já identificado. Neste caso o indivíduo encontra-se "imunizado" à doença. No máximo, após a reincidência do anticorpo, agora com o auxílio do IgG, a pessoa poderá apresentar uma resposta branda à doença, diferentemente da resposta fortemente inflamatória fornecida pelo primeiro contato e pela imediata mediação da IgM. De forma análoga, o IgE atua como o IgM, agindo imediatamente quando um agente estranho entra no organismo, entretanto, apenas o $\operatorname{IgG}$ atua como anticorpo de memória. É importante ressaltar que as vacinas atuam justamente neste princípio de memória do organismo, expondo as pessoas a baixas doses ativas de patógenos de modo a estimular a produção dos anticorpos IgG de memória (Stapel et al., 2008).

Outro conceito importante a ser definido são as intolerâncias alimentares e a associação desta com alergias. Intolerância alimentar é relacionada a disfunções no metabolismo de indivíduos, em que ocorre a falta de enzimas que quebram ligações glicosídicas, necessárias para o metabolismo de açúcares, sendo esta característica frequentemente associada à lactose. O nosso corpo obtém energia por meio da quebra de monossacarídeos, porém não diretamente de oligo ou polissacarídeos. Quando as cadeias de oligossacarídeos não são quebradas para disponibilizar os monossacarídeos, ocorrem algumas manifestações no corpo que podem ser identificadas como intolerância alimentar. Por exemplo, caso uma pessoa ingira muito leite, consequentemente lactose, suas enzimas lactase, que quebram a lactose liberando os monossacarídeos, vão atuar. Pessoas que possuem intolerância alimentar à lactose possuem uma quantidade insuficiente de lactase para processar a quantidade de lactose ingerida. Neste caso, a lactose que não for reduzida a monossacarídeos, vai diretamente do estomago para o intestino da pessoa (Nelson \& Cox, 2014).

No intestino, as lactoses vão ser fermentadas pela flora intestinal de forma anaeróbica. Essa fermentação gera alguns compostos gasosos, que levam à ocorrência de flatulências na pessoa. A ação da flora intestinal sobre a lactose cria um desequilíbrio no intestino em que, além da formação excessiva de gases, boa parte dos nutrientes naturalmente absorvidos no intestino não conseguirão mais ser absorvidos naquele momento, pois a prioridade será eliminar a lactose que não deveria estar presente. Como resultado a pessoa sente fortes dores intestinais, assim como desconfortos intestinais, levando a flatulência ou mesmo diarreia. Logo a intolerância alimentar é associada principalmente às disfunções intestinais. Vale ressaltar que a presença de um oligossacarídeo no organismo não é vista como um corpo estranho, de modo que em momento algum o sistema imunológico é ativado para combater esta substância (Bahna, 2012).

Por meio das informações acimas, observa-se assim que não há qualquer relação entre alergias e intolerância alimentar, tampouco há relação entre o sistema imunológico e a intolerância alimentar. Depreende-se também que não há relação direta entre os níveis de IgE ou IgG com intolerância alimentar.

Ressalta-se que as alergias alimentares ocorrem principalmente em crianças, porém com o devido tratamento essas condições podem desaparecer na idade adulta. Entretanto, é importante não se ater a modismos de alimentação, mediante diagnósticos inconclusivos ou pressuposições. A remoção indevida de alimentos, inclusive o leite da dieta de crianças, pode acarretar o comprometimento do desenvolvimento da criança, uma vez que os alimentos que substituem o leite podem não possuir o mesmo valor nutricional. É importante ressaltar que um diagnóstico adequado deve ser realizado para a identificação do APVL e IL, assim como, qualquer restrição alimentar deve ser acompanhada por um profissional especialista (Asbai, 2020).

Em relação à questão do diagnóstico de IL e APVL, estes são distintos e específicos, conforme apresentado ao longo do trabalho. Ressalta-se que o diagnóstico de IL é realizado a partir da medição da concentração de glicose sérica após ingestão de lactose em jejum, medição da atividade de lactase intestinal ou teste respiratório de hidrogênio (Mattar \& Mazo, 2010; Cunha et al., 2008), e o diagnóstico da APLV é realizado por testes cutâneos, aferição dos níveis séricos de anticorpos específicos (IgE) ou testes de provocação com o próprio alimento (Rocha, 2018; Santin et al., 2018). 


\section{Conclusão}

As alergias e a intolerância alimentar, sobretudo ligadas ao leite, tem se tornado uma questão de saúde pública, uma vez que interfere significativamente na qualidade de vida da pessoa acometida por essas condições. O diagnóstico deve ser realizado o quanto antes, mas deve ser tratado com cautela, visto que normalmente envolve a privação do consumo de leite, fonte de proteínas e nutrientes para os indivíduos, sobretudo as crianças. O diagnóstico precoce tem relação direta com a melhora na qualidade de vida do paciente com APLV ou IL.

Por meio do estudo realizado ressalta-se que em diversos pontos sintomáticos e clínicos existe a distinção entre alergias e intolerância alimentar. Apesar da similaridade de alguns sintomas, não há relação clínica entre o sistema imunológico e a intolerância alimentar. Também foi verificado que análises clínicas que utilizam como base a resposta de anticorpos IgG, não são adequadas para verificarem alergias ou intolerâncias alimentares. Desta o acompanhamento correto e o diagnóstico correto destas condições são de suma importância para garantir a qualidade de vida das pessoas, inclusive o bom desenvolvimento de crianças.

\section{Referências}

Andrade, D. C. M., Brum, A. K. R., \& Messias, C. M. (2020). Gestão do cuidado seguroda criança alérgica ao leite:a saúde do escolare suas perspectivas. Research, Society and Development, 9,(4), e106942899. http://dx.doi.org/10.33448/rsd-v9i4.2899

ASBAI - Associação Brasileira de Alergia e Imunologia \& Sban - Sociedade Brasileira de Alimentação e Nutrição (2012). Guia prático de diagnóstico e tratamento da Alergia às Proteínas do Leite de Vaca mediada pela imunoglobulina E. Revista Brasileira de Alergia e Imunopatologia, 35 (6), $203-232$. http://aaai-asbai.org.br/imageBank/pdf/v35n6a03.pdf

ASBAI - Associação Brasileira de Alergia e Imunologia (2016). Posicionamento do Grupo de Alergia Alimentar da ASBAI. http://www.sbai.org.br/imagebank/2016-09-26-TESTE-DE-IGG-SATEMENT-SO-ASBAI.pdf

ASBAI - Associação Brasileira de Alergia e Imunologia (2020). Diagnóstico: Alergia alimentar. https://asbai.org.br/conheca-o-passo-a-passo-para-odiagnostico-da-alergia-alimentar/

ASCIA - Australasian Society of Clinical Immunology and Allergy (2014). Unorthodox testing and treatment for allergic disorders. https://www.allergy.org.au/images/stories/aer/infobulletins/2010pdf/AER_Unorthodox_Testing_Treatment_for_Allergic_Disorders.pdf

Bahna, S. L. (2012). Cow's milk allergy versus cow milk intolerance. Annals of Allergy, Asthma \& Immunology, 86 (6), 56-60. http://dx.doi.org/10.1016/s1081-1206(10)62124-2

Barreto, R. S. M. (2010). Levantamento dos casos de intolerância a lactose e alergias alimentares nos Centros de Educação Infantis da AFASC. Trabalho de Conclusão de Curso (Bacharelado em Nutrição) - Universidade do Extremo Sul Catarinense. http://repositorio.unesc.net/bitstream/1/157/1/Renata\%20de\%20Souza\%20Manique\%20Barreto.pdf

Biosys (2008). Intolerância alimentar FoodDetective ${ }^{\mathrm{TM}}$ : Teste para intolerância alimentar mediada por IgG. http://intoleranciaalimentar.com.br/uploads/5cd8f767adc5e5622d891726e61a04b8c9a63f43.pdf

Bock, A. S. (2010). AAAAI support of the EAACI Position Paper on IgG4. Journal of Allergy and Clinical Immunology, 156 (6), 1410. http://dx.doi.org/10.1016/j.jaci.2010.03.013

Branco, M. S. C., Dias, N. R., Fernandes, L. G. R., Berro, E. C., \& Simioni, P. U. (2018). Classificação da intolerância à lactose: uma visão geral sobre causas e tratamentos. Revista de Ciências Médicas, 26 (3), 117-125. http://dx.doi.org/10.24220/2318-0897v26n3a3812

Brisotti, A. D., Lima, C. M. F., Hernandes, G. H., Barbosa, L. G., Chaddad, M. C. C., \& Yang, A. C. (2018). Dieta de restrição à proteína do leite de vaca: aderência e rotulagem dos alérgenos. Brazilian Journal of Allergy and Immunology, 2 (4), 441-446. http://dx.doi.org/10.5935/2318-5015.20180059

Calich, V., \& Vaz, C. (2009). Imunologia. ( ${ }^{\mathrm{a}}$ ed) REVINTER.

Carr, S., Chan, E., Lavine, E., \& Moote, W. (2012). CSACI Position statement on the testing of food-specific IgG. Allergy, Asthma \& Clinical Immunology, 8 (1), 1-2. http://dx.doi.org/10.1186/1710-1492-8-12

Cnf - Conselho Federal de Nutricionistas (2012). Parecer Técnico No. 018-A/2012 - UT/CFN: Realização do teste food detective por nutricionistas.

Costa, E., Varrengea, E. C., \& Nardo, P. A. (2012). Alergia alimentar na infância. Revista Uningá, 31, 85-92. http://revista.uninga.br/index.php/uninga/article/view/999/659

Cunha, M. E. T., Suguimoto, H. H., Oliveira A. N., Sivieri, K., \& Costa M. R. (2008) Intolerância à lactose e alternativas tecnológicas. UNOPAR Cientifíca. Ciências biológicas e da saúde, 10 (2), 83-88. https://revista.pgsskroton.com/index.php/JHealthSci/article/view/1523/1460

Ferreira, S., Pinto, M., Carvalho, P., Gonçalves, J.-P., Lima, R., \& Pereira, F. (2014a). Alergia às proteínas do leite de vaca com manifestações gastrointestinais. Nascer e Crescer, 22 (2), 72-79. https://revistas.rcaap.pt/nascercrescer/article/view/8601/6154 
Ferreira, C. T., Carvalho, E., Sdepanian, V. L., Morais, M. B., Vieira M. C., \& Silva, L. R. (2014b). Gastroesophageal reflux disease: exaggerations, evidence and clinical practice. Jornal de Pediatria, 90 (2), 105-117. http://dx.doi.org/10.1016/j.jpedp.2013.05.010

Franco, J. M., Pinheiro, A. P. S. G., Vieira, S. C. F., Barreto, I. D. C., Gurgel, R. Q., Cocco, R. R., \& Solé, D. (2018). Accuracy of serum IgE concentrations and papule diameter in the diagnosis of cow's milk allergy. Jornal de Pediatria, 94 (3), 279-285. http://dx.doi.org/10.1016/j.jped.2017.06.022

Garcia, F. B., Mota, I., Piedade, S., \& Morais-Almeida, M. (2016). Alergia às Proteínas do Leite de Vaca: Uma Nova Era. Gazeta Médica, 3 (1), $28-31$. http://dx.doi.org/10.29315/gm.v3i1.8

Gasparin, F. S. R., Carvalho, J. M. T., \& Araújo, S. C. (2010). Alergia à proteína do leite de vaca versus intolerância à lactose: as diferenças e semelhanças. Revista de Saúde Pública, 3 (1), 107-114. https://periodicos.unicesumar.edu.br/index.php/saudpesq/article/view/1069/1045

Grenov, B., Briend, A., Sangild, P. T., Thymann, T., Rytter, M. H., Hother, A.-L., Mølgaard, C., \& Michaelsen, K. F. (2016). Undernourished children and milk lactose. Food and Nutrition Bulletin, 37 (1), 85-99. http://dx.doi.org/10.1177/0379572116629024

Lopes, A. L. C., Amancio, O. M. S., \& Oliveira F. L. C. (2020). Consumo do leite de vaca de 0 a 36 meses de idade. Sociedade Brasileira de Alimentação e Nutrição - SBAN. http://www.sban.org.br/uploads/DocumentosTecnicos20200318045413.pdf

Mattar, R., \& Mazo, D. F. C. (2010). Intolerância à lactose: mudança de paradigmas com a biologia molecular. Revista da Associação Médica Brasileira, 56 (2) 230-236. http://dx.doi.org/10.1590/s0104-42302010000200025

Moratoya, E. E., Carvalhaes, G. C., Wander, A. E., \& Almeida, L. M. M. C. (2013). Mudanças no padrão de consumo alimentar no Brasil e no mundo. Revista de Política Agrícola, 22 (1), 72-84. https://ainfo.cnptia.embrapa.br/digital/bitstream/item/86553/1/Mudancas-no-padrao-de-consumo-alimentar-no-Brasil-e-nomundo.pdf

Muniz, L. C., Madruga, S. W., \& Araújo, C. L. (2013). Consumo de leite e derivados entre adultos e idosos no Sul do Brasil: um estudo de base populacional. Ciência \& Saúde Coletiva, 18 (12), 3515-3522. http://dx.doi.org/10.1590/s1413-81232013001200008

Nelson, D. L., \& Cox, M. M. (2014). Princípios de bioquímica de Lehninger. (6a ed.) Artmed.

Neves, F. V. O., Beck, C. M. L., Gushken, A. K. F., Yonamine, G. H., Castro, A. P. B. M., Dorna, M. B., Santos, C. J. N., \& Pastorino, A. C. (2016). Cow's milk allergy: Evaluating tolerance through skin-prick test. Revista da Associação Médica Brasileira, 62 (6), 537-543. http://dx.doi.org/10.1590/18069282.62.06.537

Pereira, A. S., Shitsuka, D. M., Parreira, F. J., \& Shitsuka, R. (2018). Metodologia da pesquisa científica, UFSM. https://repositorio.ufsm.br/bitstr eam/handle/1/15824/Lic_Computacao_Metodologia-Pesquisa-Cientifica.pdf?sequence=1

Ramos, R. E. M., Lyra, N. R. S., \& Oliveira, C. M. (2013). Alergia alimentar: reações e métodos diagnósticos. Journal of Management \& Primary Health Care, 4 (2), 54-63. http://dx.doi.org/10.14295/jmphc.v4i2.170

Rocha, R. L. (2018). Alergia ao leite de vaca: mecanismo, diagnóstico e perspectivas biotecnológicas. Infarma - Ciências Farmacêuticas, 30 (1), $60-66$. http://dx.doi.org/10.14450/2318-9312.v30.e1.a2018.pp60-66

Santin, C., Amaral, G. S., \& Gelinski, J. L. N. (2018) Alergia à proteína do leite de vaca (APLV). Anuário Pesquisa e Extensão Unoesc Videira, 3 , e19914. https://portalperiodicos.unoesc.edu.br/apeuv/article/view/19914/10573

Santos, M. F., Rocha, S. M. O., \& Carvalho, A. M. R. (2019). Avaliação da prevalência de crianças com alergia a proteína do leite de vaca e intolerância à lactose em um laboratório privado de Fortaleza - CE. Revista Saúde-UNG-Ser, 12 (1/2), 41-46. http://dx.doi.org/10.33947/1982-3282-v12n1-2-3466

Silva, C. J., Leite, I. D. S., Rodrigues, W., Almeida, S. P., Nóbrega, B. P., \& Filho, J. D. R. S. (2019). Analysis of lactose intolerance in students with suggestive symptoms of irritable bowel syndrome. Arquivos de Gastroenterologia, 56 (3), 304-311. http://dx.doi.org/10.1590/s0004-2803.201900000-57

Souza, A. M., Pereira, R. A., Yokoo, E. M., Levy, R. B., \& Sichieri, R. (2013). Alimentos mais consumidos no Brasil: Inquérito nacional de alimentação 20082009. Revista de Saúde Pública, 47 (1), 190-199. http://dx.doi.org/10.1590/s0034-89102013000200005

Stapel, S. O., Asero, R., Ballmer-Weber, B. K., Knol, E. F., Strobel, S., Vieths, S., Kleine-Tebbe, J., \& EAACI Task Force (2008). Testing for IgG4 against foods is not recommended as a diagnostic tool: EAACI Task Force Report. Allergy, 63 (7), 793-796. http://dx.doi.org/10.1111/j.1398-9995.2008.01705.x

Toméi, M. C. M. (2016). Lactose: Intolerância, Alergia e Rotulagem de Alimentos. Revista Científica Multidisciplinar Núcleo do Conhecimento, 9, 99-110. https://www.nucleodoconhecimento.com.br/nutricao/lactose-intolerancia 